\title{
Comparison of Phenotypic and Genetic Performance of Local Silkworm Groups and Two Commercial Lines
}

\author{
Seyed Ziaeddin Mirhosseini ${ }^{1 *}$, Shahla Nematollahian², Mani Ghanipoor ${ }^{3}$ and Alireza Seidavi ${ }^{4}$ \\ 1 Animal Science Department, Faculty of Agriculture, Guilan University, Rasht, Iran \\ 2 Iran Silkworm Research Center, Rasht, Iran \\ 3 Iran Silkworm Research Center, Rasht, Iran \\ ${ }^{4}$ Islamic Azad University, Rasht Branch, Rasht, Iran, E-mail: alirezaseidavi@iaurasht.ac.ir
}

\begin{abstract}
Five Iranian native silkworm groups: Baghdad, Khorasan Orange, Guilan Orange, Khorasan Pink, Khorasan Lemon, and 107 and 110 commercial lines (12 families from each breed) were randomly selected and reared during 2003-2005 (five generations in spring and autumn). In each family, 30 male and 30 female cocoons were individually recorded for weight, shell weight and shell ratio. From among the native groups, the highest average in all three traits belonged to Baghdad and Khorasan Pink, and the lowest to Khorasan Orange and Khorasan Lemon. From among the commercial lines, the highest average in all three traits belonged to 107. In comparing heritability for cocoon weight in native groups, the highest heritability belonged to Guilan Orange (0.5147) and Khorasan Orange (0.5036) and the lowest heritability belonged to Khorasan Pink (0.0967). In the two other traits, the highest heritability belonged to Khorasan Orange and Baghdad and the lowest to Khorasan Pink. In the commercial lines, line110 had higher heritability than line107 for cocoon weight and cocoon shell weight. In all the groups, genetic correlations between cocoon weight and cocoon shell weight were high, expect for the Baghdad group. There was medium or low genetic correlation among cocoon weight, cocoon shell weight and cocoon shell ratio.
\end{abstract}

Key terms: native silkworm, commercial lines, Bombyx mori L., heritability, genetic correlation.

\section{INTRODUCTION}

The first stage of breed improvement for producing silkworm eggs at the commercial level is separating net lines from native breeds or imported hybrids (ESCAP, 1993). Production of native silkworms at present is not economical owing to very low performance. Some combinations resulting from improved lines are used for producing silk at the commercial level (Mirhosseini, 1998). Native breeds with geographic and reproductive limits over generations have been adapted to environmental conditions and tensions arising from nutritive limitations related to where they live as the result of a natural choice. As well, relative resistance to native and regional diseases is an important advantage of these creatures. In the most cases, the animals that are reared under unfavorable environmental conditions, choose actions that are contrary to their economically desirable characteristics. Consequently, these animals do not have the same production levels as breeds selected in favorable environmental conditions. Meanwhile, evaluation of native animals should be based on their total economic capacity, including product output in lieu of the monetary value of the production (Mirhosseini, 1990).

Another reason for considering native animals is maintaining gene banks and preventing the native breeds from decreasing or decaying (Anonymous, 1996). The existence of native animal banks provides a valuable genetic base to specialists for breed improvement, so that with time and changing needs, we can still draw on this resource in the future (Mirhosseini, 1998). Consequently, maintaining gene banks of native animals is a priority of the Food and Agriculture Organization (FAO) (Anonymous, 1996).

Diversity is the observation of different forms and functions among species. However, this definition is too narrow and fails to recognize that individuals within a species also differ in many phenotypes. These phenotypes may be qualitative, such as cocoon color, or quantitative, such as cocoon weight. With animals with an economic value, particular phenotypes have evolved because of their utility to particular human populations. The most useful concept in quantifying these differences is the fundamental statistical concept of variance, since it can be broken down into sub components, and in particular, if we have a sum of independent variables, each with some variance, the variance in the sum of the variables is equal to the sum of the variances (Oldenbroek, 2007).

The influence of environmental heterogeneity on economically relevant traits has largely been tested. In systems where the role of environmental heterogeneity has been examined, findings suggest that studying traits without taking environmental heterogeneity into consideration leads to false conclusions. For example, in bulb mites, a structurally more complex environment results in lower survival for scrambler males, resulting in a higher frequency of fighters than found in simpler environments (Lukasik et al., 2006).

Different genetic groups of silkworms have been the subject of study for the purpose of recognition and improvement of their genetic characteristics. Some studies have been undertaken in Iran about varieties and import lines and native groups of silkworms in the country. Amu Oghli Tbari (1997), through studying and evaluating some economically relevant characteristics of 4 lines of silkworm and the nutritive effect of 3 varieties of mulberry, argued that the effect of line and variety for many of productive and economic characteristics of this insect are meaningful. 
Murakami (1994) reported some methods for breedimprovement of varieties of silkworm to adapt them to the environmental conditions of the region. Grekov (1989) considered the characteristics of some traits in 6 varieties of silkworm. He emphasized that average and finite change of each trait varies and found the greatest diversity in fiber length and cocoon weight. He noted that there is a strong mutual effect of environment and genotype and that cocoon shell weight has a positive correlation with cocoon weight $(+0.659)$. He argued that selection should be based on cocoon shell weight, but also cocoon weight and fiber length should be taken into consideration. Petcov (1989) also considered genetic characteristics of new varieties of silkworm and found that correlation of cocoon shell weight with cocoon weight in new lines is in the range of 0.653 to 0.528 . He proposed line selection based on shell weight, but cocoon weight and fiber length should be also under consideration.

Genetic variability for economical traits is the key component of breeding programmes for broadening the gene pool of silkworm. However, the genetic variability for many traits is limited in cultivated germplasm. The genetic basis of changes associated with rice domestication was studied very little. It is imperative that a detailed understanding of genetic information about yield traits, such as heritability, and genetic and environmental effects, be addressed properly before undertaking any genetic improvement programmes (Sabu et al., 2009).

Previously, Mirhosseini et al (2006) and Ghanipoor et al (2007) reported that silkworm cocoon traits like cocoon weight, cocoon shell weight and cocoon shell ratio have high economic potential, values and heritabilities, and farmer incomes are based on total cocoon weight and hence cocoon traits are the most important economical traits in sericulture. There is little information about the heritability and correlations of cocoon traits of Iranian native breeds. The use of subjective traits as breeding objectives without knowledge of their relationships to other economically important traits could be counterproductive if correlations prove to be antagonistic. At the least, selection based on subjective traits could be ineffectual if genetic correlations are favorable but low. This experiment presents heritability estimates as well as genetic, phenotypic and environmental correlations in cocoon economical traits. The purpose of this plan is to consider genetic characteristics of 5 native silkworm groups native to Iran and compare them to commercial lines. In the process, the genetic capacities of important traits of this insect were considered.

\section{MATERIALS AND METHODS}

Five native Iranian silkworm groups, including Baghdad, Khorasan Orange, Guilan Orange, Khorasan Pink, Khorasan Lemon, and the commercial lines 107 and 110 (12 families in each group) were selected and reared during the years 20032005 (five generations in spring and autumn). In the spring, egg-rearing with hibernation was used and in autumn eggrearing without hibernation was used. After the transition from larva to pupate, the cocoons spun by each groups were harvested separately and cleaned of floss. In each family, 30 male cocoons and 30 female cocoons were individually recorded for cocoon weight (gr), shell weight (gr) and shell ratio (\%), then the families in each groups were crossed together randomly. As well, in each group the families were selected based on the hatchability ratio of eggs produced per molt. In later generations, each of the groups was reared under the standard conditions until the end of larval development. The collected data were subjected to statistical variance analysis to find the lowest significant difference between each set of treated groups. For all analyses of variance, Duncan's multiple range tests were used with SPSS software.

The statistical model used was as follows (Meyer, 1988; Seidavi, 2010):

$$
y_{i j k l}=\mu_{i}+S_{i j}+G_{i k}+L_{i j k l}+e_{i j k l}
$$

To estimate genetic parameters in all of the groups, the following model was used (Meyer, 1988; Seidavi, 2010):

$$
y_{i j k l m}=\mu_{i}+S_{i j}+G_{i k}+L_{i l}+A_{i j k l m}+e_{i j k l m}
$$

The signs used in the model were as follows: Y: the animal's record, mi: the mean of ith trait, Sij: the effect of jth sex of the ith trait, Gik: the effect of the kth generation and ith trait, Lil: the effect of the lth line and ith trait, A: additive genetic value of the animal and e: the effect of remaining factors (Meyer, 1988; Seidavi, 2010).

In this model, the effects of sex, generation and line are fixed and additive genetic value of animals and remaining factors are random effects. As well, heritability and additive genetic correlations of traits were estimated by the REML method by using a derivative free algorithm in the animal model on the basis of full sib's data (Meyer, 1988; Seidavi, 2010).

\section{RESULTS AND DISCUSSION}

All of the fixed factors and the effect of interactions among them were highly significant for all characters $(p<0.001)$ except the effect of generation $x$ sex in cocoon shell ratio (Table 1).

The comparison of means for all traits of native groups and commercial lines are shown in Figures 1,2 and 3. Highly significant variability for cocoon characteristics can be observed. From among the native groups, Baghdad and Khorasan Pink had the highest means for cocoon weight (1.55 gr for both) compared to Guilan Orange and Khorasan Lemon with the lowest means (both $1.33 \mathrm{gr}$ ). As well, there was a high significance between lines 107 and 110, with higher means for 107 for all traits. In shell weight, among the native groups, Khorasan Pink and Baghdad were the highest, with 0.288 and 0.255 , respectively. Guilan Orange and Khorasan Lemon were the lowest, with 0.202 and 0.189 , respectively. In shell ratio, Khorasan Pink and Baghdad were the highest, with 18.70, 16.52 respectively, and Guilan Orange and Khorasan Lemon were the lowest, with 15.19 and 14.35, respectively. All of groups had the same performance in all the traits. Though cocoon weight is important economically, shell weight is used as silk material. Then, although Khorasan Pink and Baghdad were equal in cocoon weight, Khorasan Pink had higher means than Baghdad in shell weight and shell ratio. As well, Khorasan Lemon, Guilan Orange and Khorasan Orange, as well as 110, 
had non-significant in cocoon weight, but Guilan Orange and 110 had high means in shell weight and shell ratio.

Table 2 shows heritability and genetic correlation of productive traits by separating different groups of native silkworm from the commercial Iranian lines. Heritability of cocoon weight in native groups was highest with (0.5147) in Guilan Orange and (0.5036) in Khorasan Orange, respectively. The lowest level was in Khorasan Pink (0.0967). The trait of cocoon shell weight was highest in Khorasan Orange (0.5314) and Baghdad (0.3030) and lowest in Khorasan Pink (0.1074).

Groups of Khorasan Orange (0.2610) and Baghdad (0.1134) had the highest and Khorasan Pink (0.0607) had lowest heritability for the trait of cocoon shell percentage. In native Iranian silkworms (except for Khorasan Orange), heritability of cocoon shell percentage is lower than cocoon weight and cocoon shell weight. In commercial lines, the heritability of line 110 for the two traits of cocoon weight and cocoon shell weight was higher than those of line 107. Ashoka et al., (1990), Jayaswal et al., (2000) and Rangaiah et al., (1995) have also reported high heritability of cocoon weight and cocoon shell weight in their research. The high genetic correlation of cocoon weight and cocoon shell weight in table 2 confirms this conclusion. Therefore in native groups, except Guilan Orange and Khorasan Lemon, heritability of cocoon shell weight was higher than cocoon weight. High heritability of the two traits of cocoon weight and cocoon shell weight shows a high effect of diversity arising from additive genes on the above-mentioned traits that indicates high efficiency of selection on the mentioned traits, and as a result their more rapid improvement. Whenever several economic traits are under consideration in reforming the breed of a species, knowledge about correlations of these traits is very important.

Table 1

The analysis of variance of economic traits

\begin{tabular}{|c|c|c|c|c|c|c|c|}
\hline \multicolumn{2}{|c|}{ Shell Ratio (\%) } & \multicolumn{2}{|c|}{ Shell Weight $(\mathrm{g})$} & \multicolumn{2}{|c|}{ Cocoon Weight $(\mathrm{g})$} & \multirow[b]{2}{*}{$\mathrm{df}$} & \multirow[b]{2}{*}{ Source } \\
\hline $\operatorname{Pr}>F$ & F & $\operatorname{Pr}>\mathrm{F}$ & $\mathrm{F}$ & $\operatorname{Pr}>\mathrm{F}$ & F & & \\
\hline 0.000 & 133588.8 & 0.000 & 47.76 .06 & 0.000 & 86319.74 & 7 & Line \\
\hline 0.000 & 321.539 & 0.000 & 972.016 & 0.000 & 956.379 & 4 & Generation \\
\hline 0.000 & 6828.672 & 0.000 & 87.365 & 0.000 & 6510.076 & 1 & Sex \\
\hline 0.000 & 14.586 & 0.000 & 34.145 & 0.000 & 39.321 & 23 & Line $\times$ Generation \\
\hline 0.000 & 26.874 & 0.000 & 4.381 & 0.000 & 6.459 & 6 & Line $\times$ Sex \\
\hline 0.101 & 1.941 & 0.000 & 5.410 & 0.000 & 20.901 & 4 & Sex $\times$ Generation \\
\hline
\end{tabular}

Table 2

Heritability and genetic correlations among traits in natives group and commercial lines

\begin{tabular}{|c|c|c|c|c|}
\hline Cocoon Shell Ratio & Cocoon Shell Weight & Heritability $\left(\mathrm{h}^{2}\right)$ & Traits & Native Group Line \\
\hline 0.7839 & - & 0.6074 & Cocoon shell weight & \\
\hline 0.2397 & 0.8677 & 0.6753 & Cocoon weight & 110 \\
\hline 0.1196 & - & 0.6342 & Cocoon shell weight & \\
\hline- & - & 0.4553 & Cocoon shell ratio & \\
\hline 0.8405 & - & 0.3030 & Cocoon shell weight & \\
\hline- & - & 0.1134 & Cocoon shell ratio & \\
\hline-0.5582 & 0.9162 & 0.5147 & Cocoon weight & Guilan Orange \\
\hline-0.3136 & - & 0.1885 & Cocoon shell weight & \\
\hline- & - & 0.0897 & Cocoon shell ratio & \\
\hline 0.085 & 0.9263 & 0.2396 & Cocoon weight & Khorasan Lemon \\
\hline 0.9273 & - & 0.5314 & Cocoon shell weight & \\
\hline- & - & 0.2610 & Cocoon shell ratio & \\
\hline 0.2659 & 0.8665 & 0.0967 & Cocoon weight & Khorasan Pink \\
\hline 0.9940 & - & 0.1074 & Cocoon shell weight & \\
\hline- & - & 0.0607 & Cocoon shell ratio & \\
\hline
\end{tabular}




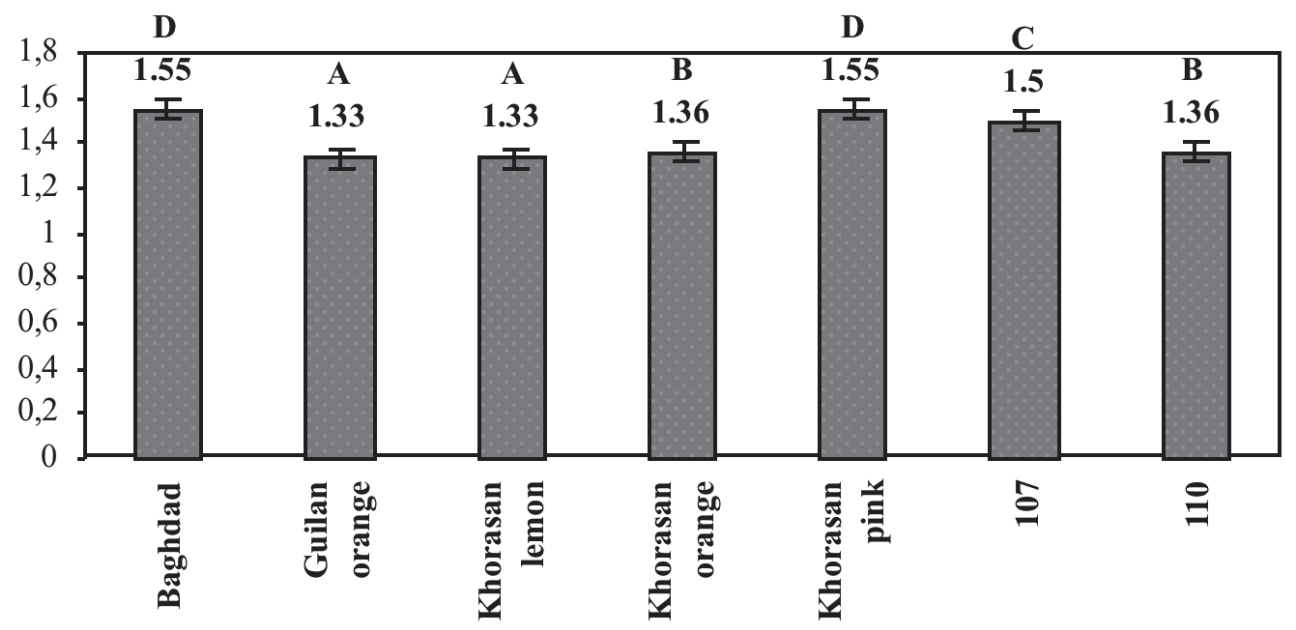

Fig 1. Means comparison of cocoon weight $(\mathrm{g})$ in native Iranian groups and commercial lines

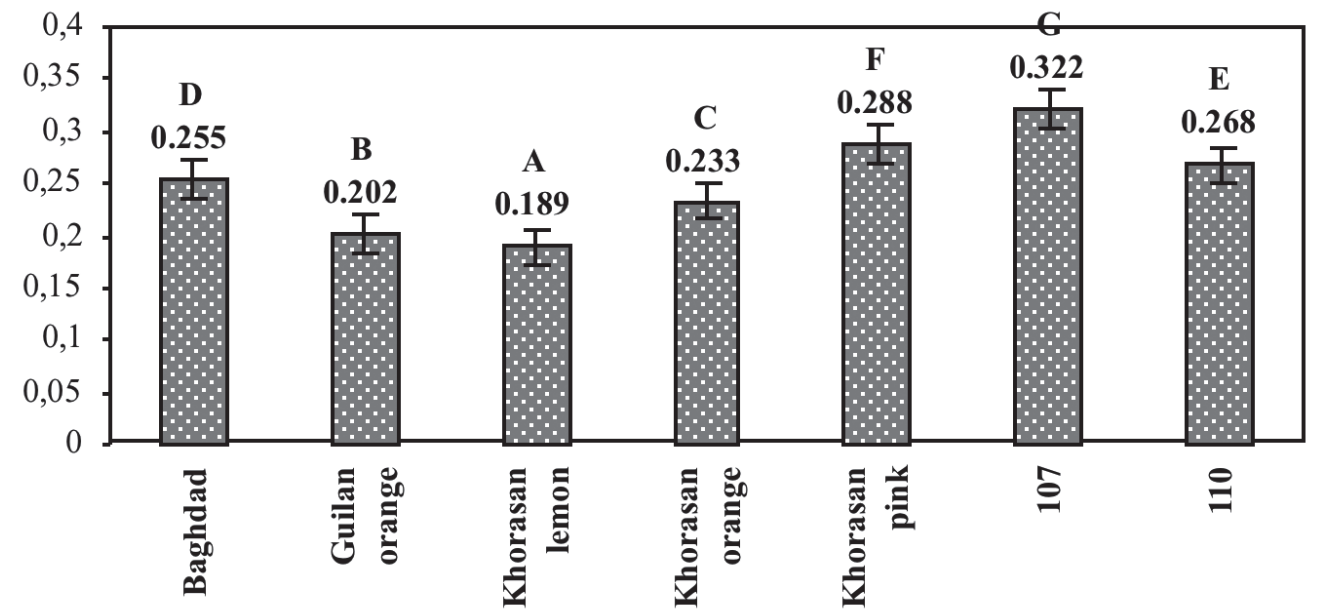

Fig 2. Means comparison of shell weight $(\mathrm{g})$ in native Iranian groups and commercial lines

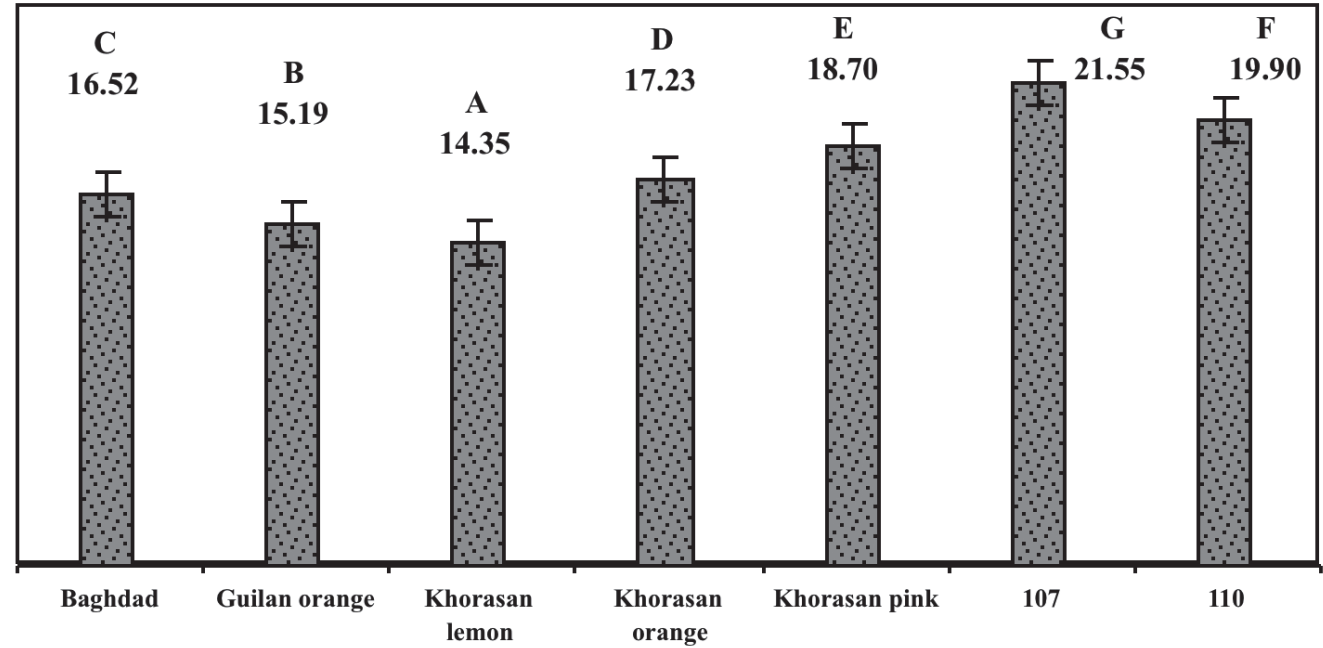

Fig 3. Means comparison of shell ratio (\%) in native Iranian groups and commercial lines 
Positive and high genetic correlation of the two important and economic traits of cocoon weight and cocoon shell weight indicates that selection for cocoon weight will lead to increased cocoon shell weight. The least correlation was observed in Baghdad group and in other groups the amount of correlation was high.

There was clear evidence of genotype-environment interaction for some traits in this study. This was shown in a number of ways: by the $\mathrm{ge}^{2}$ value being different from zero. The general level of the effect was rather low. On the basis of the results from the current dataset, the level of the genotype-environment effect would seem to be of little practical value. However, there were clearly some silkworm lines that did change their breeding values in different environments, and some appeared to have a negative random regression slope. The low level of the genotypeenvironment effect may have been due to a range of factors (Pollott and Greeff. 2004).

The traditional way of estimating heritability, a point estimate for any given dataset, has become the norm. However, heritability was originally defined to relate only to the population under study in the environment in which it was found (Falconer, 1981), and a range of values is to be expected. The use of reaction norm models makes it possible to revisit the idea of the heritability of a trait being related to a particular flock environment in a more systematic and comparable way than has been possible previously. At low values of the environmental variable, the genetic variability of the traits was high, implying that some individuals have the genetic ability to cope with poor conditions better than others. Under a range of relatively benign environments, the variability of breeding variables is stable and less than in the poor environments (Pollott and Greeff. 2004).

Modeling gene-gene interactions in linkage analysis may improve the power to detect chromosomal regions harboring interesting trait genes. Linkage analysis methods that model interactions may increase the statistical power to detect linkage when interactions among genes exist. For example, under a two-locus epistatic model, the power to detect linkage at one susceptibility locus would increase if we assess the linkage among families that are linked at another susceptibility locus and vice versa. Several published studies have empirically demonstrated the increased power to detect linkage by modeling gene-gene interactions (Chang et al., 2006).

Additive genetic effects consist of the effects of two or more alleles of different loci combined in such a way that the sum of their effects in unison is equal to the sum of their effects individually. Such phenomena are only possible when the alleles involved do not interact with one another in such a way that they modify, hinder, or amplify the effects of any gene involved. An additive genetic effect is a form of quantitative inheritance as the effects of the combined genes can be simply added together. Additive genetic effects are different from cumulative gene action because in the latter, the effects of the genes combined create an action of increased intensity.

Genetic diversity protects a species against extinction by providing multiple phenotypes. These phenotypic differences may provide disease resistance, adaptability to a changing climate, or some other trait necessary for the species to survive in the ever-changing world. Maintaining genetic diversity within a species is important for maintaining yield stability and ability to adapt to everchanging environmental challenges and diseases. Much of the increase in animal production in the last 50 years comes from improved varieties achieved through breeding, drawing on existing genetic diversity. Hence, it is very important that we recognize and identify performance potential of native silkworm breeds as a commercially relevant insect.

The present conclusions are the same as those reported by Satenahalli et al., (1990) and Sofi et al., (1999). A middle or low correlation was observed among traits of cocoon weight, cocoon shell weight and cocoon shell percentage. There was a negative correlation between cocoon weight and the two other traits in the Guilan Orange group. Meanwhile, there was a high and positive genetic correlation between traits of cocoon shell weight and cocoon shell percentage in the groups of Khorasan Lemon (0.924), Khorasan Orange (0.927) and Khorasan Ping (0.994).

\section{CONCLUSIONS}

It is concluded that there are different correlations and heritabilities among native silkworm lines. Native breeds have low production potential in comparison to commercial lines. However, native breeds have high resistance and rare genes that can be used to increase resistance to disease and unfavorable environmental conditions in future breeding programs. Thus, separate breeding strategies and selection programs must be designed for each variety. As well, economic traits have high heritability in commercial varieties and low heritability in native varieties, showing that selection programs cannot be performed efficiently to improve important traits in native breeds. Today silkworm lines are selected based mostly on genetic characteristics e.g. general combining ability and special combining ability. Furthermore, there have been reports regarding this concept and more attention must be given to these genetic resources. Finally, the results obtained showed that cocoon weight and cocoon shell weight have high heritability and cocoon shell ratio has lower heritability. These results emphasis additive gene effects on cocoon weight and cocoon shell weight traits, while the cocoon shell ratio is controlled by non-additive gene effects.

\section{ACKNOWLEDMENT}

The present experiment was conducted with support of the Iran Silkworm Research Center (ISRC). The authors wish to thank staff of the ISRC for their technical insights and support throughout the course of this project.

\section{REFERENCES}

AMU OGHLI TABARI M (1997) Studying and evaluating some economic traits of 4 important lines of silkworms and their nutritive effect from three varieties of mulberry. Thesis of MSc degree in Entomology, Isfahan Industrial University. 112pp.

ANONYMOUS (1996) Primary document for development of national farm animal resources management plans. IDAD, FAO PGD-1.0.

ASHOKA J, GOVINDAN R (1990) Genetic estimates for quantitative traits in bivoltine silkworm, Bombyx mori L. Mysore J Agricul Sci 24: 371374.

CHANG BL, LANGE EM, DIMITROV L, VALIS CJ, GILLANDERS EM, 
LANGE LA, WILEY KE, ISAACS SD, WIKLUND F, BAFFOEBONNIE A, LANGEFELD CD, ZHENG SL, MATIKAINEN MP, IKONEN T, FREDRIKSSON H, TAMMELA T, WALSH PC, BAILEYWILSON JE, SCHLEUTKER J, GRONBERG H, COONEY KA, ISAACS WB, SUH E, TRENT JM, XU J (2006) Two-locus genome-wide linkage scan for prostate cancer susceptibility genes with an interaction effect. Hum Genet 118: 716-724.

ESCAP (1993) Principles and techniques of silkworm breeding. United Nations, New York. 114pp.

FALCONER DS (1981) Introduction to Quantitative Genetics. 2nd ed. Longman, London, U.K.

GHANIPOOR M, SHADPARVAR AA, MIRHOSSEINI SZ, SEIDAVI AR (2007) Estimation of economic values of productive and reproductive traits for three Iranian commercial silkworm lines in minimum cost interest. J Agricul Sci, Guilan University. 1(7): 45-57.

GREKOV D (1989) Selection-genetic evaluation of some white cocoon races of the silkworm (Bombyx mori L.). Heritability and Genetic correlations of qualitative traits. Zhivotnov'dni Nauki. 26(3): 70-73.

JAYASWAL KP, MASILAMAN S, LAKSHMANAN V, SINDAGI SS, DATTA RK (2000) Genetic variation, correlation and path analysis in mulberry silkworm, Bombyx mori L. Sericologia, 40: 211-223.

LUKASIK P, RADWAN J, TOMKINS JL (2006) Structural complexity of the environment affects the survival of alternative male reproductive tactics. Evolution. 60: 399-403.

MEYER K (1988) DFREML. Programs to estimate variance components for individual animal models by restricted maximum likelihood. User notes. Edinburgh Univiversity, Edinburgh, Scotland.

MIRHOSSEINI SZ, GHANIPOOR M, SHADPARVAR AA, SEIDAVI AR, BIZHANNIA AR (2006) Study on Deriving Economic Values for Selection Indices in Silkworm, Bombyx mori L. Sericologia. 46(3): 257263.

MIRHOSSEINI SZ (1990) Estimation of genetic potential of Iran native hen in half-industrial conditions and its comparison with rural conditions,
Thesis of MSc. degree, faculty of agriculture teacher training university (Tarbiat Modarres University), Tehran, Iran, 125 pp.

MIRHOSSEINI SZ (1998) Considering Iran silkworm genetic diversity using of protein and DNA indicators, thesis of PhD degree in animal sciences, Tarbiat Modarres University, Tehran, Iran, $162 \mathrm{pp}$.

MURAKAMI A (1994) Growth phenomena in Bombyx mori L. with a special reference to genetic factors responsible for growth acceleration and moultinism. Indian J Sericulture. 33: 12-14.

OLDENBROEK K (2007) Utilisation and Conservation of Farm Animal Genetic Resources. Wageningen Academic Publishers. 232 PP.

PETKOV N (1989) Improving the initial breeds of the regionally distributed hybrid Hessa 1 X Hessa 2 intended for spring industrial silkworm feedings. II. Correlations between quantitative breeding characters. Genetika Selektsiya. 22(6): 536-540.

POLLOTT GE, GREEFF JC (2004) Genotype x environment interactions and genetic parameters for fecal egg count and production traits of Merino sheep. J Animal Sci 82: 2840-2851.

RANGAIAH S, GOVINDAN R, DEVAIAH MC, NARAYANASWAMY TK (1995) Genetic studies for some quantitative traits among multivoltine races of silkworm, Bombyx mori L. Mysore J Agricul Sci 29(3): 248-251.

SABU KK, ABDULLAH MZ, LIM LS, WICKNESWARI R (2009) Analysis of heritability and genetic variability of agronomically important traits in Oryza sativa x O. rufipogon cross. Agronomy Res 7: 97-102.

SATENAHALLI SB, GOVINDAN R, GOUD JV, MAGADUM SB (1990) Genetic parameters and correlation coefficient analysis in silkworm, Bombyx mori L. Mysore J Agricul Sci 24: 491-495.

SEIDAVI AR (2010) Investigation on effect of individual selection based on cocoon weight on additive genetic value and selection index value in six commercial silkworm pure lines. World J Zool 5: 7-14.

SOFI AM, MASOODI MA, KAMALI AS (1999) Estimation of heritability and correlation of some quantitative traits in line 'tester analysis in silkworm, Bombyx mori L. Mysore J Agricul Sci 33: 289-296. 